\title{
The Effect of Surface Roughness of Low Carbon Steel by Heat Treatment in Turning Operation
}

\author{
Abdullah Tariq AL-Malki, Dr. Basim A. Khidhir
}

\begin{abstract}
This research focuses on enhancing the surface roughness of low carbon steel by heat treatment of low carbon steel in turning operation. Heat treatment is mainly used to improve the mechanical properties of materials. Two sets of specimens used during the experiment where each has 5 pieces of mild steel that heat-treated of two-level of temperatures of $650{ }^{\circ} \mathrm{C}$ and $900^{\circ} \mathrm{C}$. After the heating process of all specimens, it will be exposed to different coolant media which are quenching, normalizing and annealing. A carbide single-point tool, one level of cutting parameters selected as one level of cutting speed and depth of cut and two levels of feed rate used during this research. The results show that specimen quenched by oil bath measures the highest value of the surface roughness of $8.26 \mu \mathrm{m}$ at $900 \mathrm{oC}$ and machined with a feed rate of $0.113 \mathrm{~mm}$. While quenched water specimens show less surface roughness of $4.91 \mu \mathrm{m}$ at $650 \mathrm{oC}$ in the same feed rate.
\end{abstract}

Keywords: Surface roughness, low carbon steel, heat treatment, turning operation

\section{Introduction}

Heat treatment process effect on the materials grains and structure. Usually heat treatment is made on carbon alloy steel and carbon steel materials for the purpose of enhancing its mechanical properties like the tensile and the yield strength to improve its hardness. Different quenching or heating routines can either soften or harden the steel. (Harvey, 2018) The specimen which will be used in the experiment is made of mild steel, mild steel is also called 'low carbon steel' because it contain a low amount of carbon. The carbon amount which is founded in mild steel is $0.05 \%-0.25 \%$ approximately. Usually carbon steel is used in screws, bolts, nuts and girders. Low carbon steel is known that it's wieldable, machinable and ductile than the high carbon steel and other steels. In this project, two temperatures will be selected to conduct all experiment. After the oven step which means after decreasing the temperature, three different coolant methods will be used which are: quenching, annealing and normalizing. The quenching will be done for three times each will have a different water solution, salted water and oil.

\section{Literature review \\ Mild Steel}

is the most common material of steel is mild steel it's also the most used steel and at the same time not brittle, as for its price it's considered relatively low comparing with the other materials. Mild steel actually provides a material properties which is normally acceptable for several different applications. The chemical composition of mild steel that it contain $0.16 \%$ to $0.18 \%$ ( the maximum amount of carbon that's allowable is $0.26 \%$ ), manganese could reach up to $0.70 \%$ or $0.90 \%$, silicon $0.40 \%$ is the maximum percentage and phosphorus $0.04 \%$ maximum percentage. Mild steel is included in the low carbon steel category. Steel that's included in the low carbon steel category approximately contains maximum $0.30 \%$ of carbon which is the 5 maximum percentage, Figure 1 shows the shape of mild steel bars. (Bin Ramli, 2018)

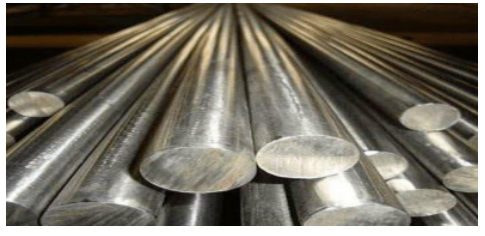

Figure 1 mild steel bars

ISSN: $2167-1907$
Mild steel is distinguished from other steels its more ductile, wieldable and machinable than high carbon and other steels, nearly impossible to strengthen and harden during heating and quenching, less tensile strength, high amounts of ferrite and iron, making it magnetic. Also mild steel is relatively affordable compared to other steels and it's subjected to oxidation if it wasn't coated properly. Mild steel is used in different regions, its especially desirable for construction because of its machinability and weldability due to its high strength and malleability, it has certain softness. Which means that mild steel can be machined easily comparing with harder steel. Mild steel is repeatedly used whenever large amount of steel is needed, for an example structural steel. Mild steel is used as mentioned previous in the construction steel, cars, street signs (furniture) and domestic goods. Fence posts, plates, wire, key ring, and tin cans almost anything you can think of. (Yahoo Oath, 2019). In this research the turning operation will conduct on the specimen is similar to what is shown in Figure 2 which will be conduct on CNC lathe machine.

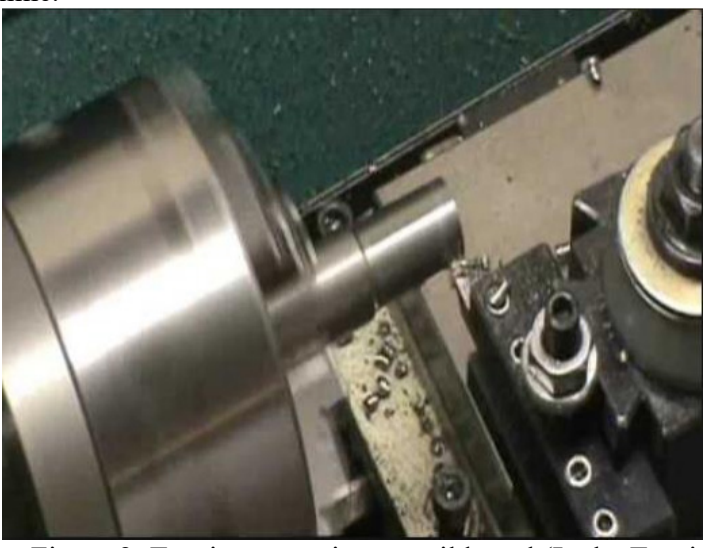

Figure 2: Turning operation on mild steel (Lathe Turning Steel, 2019)

\section{Heat treatment}

Heat treatment is the process which a metal is heated up to a particular temperature and cooled in a certain manner to change its structure to achieve the certain degree to change its mechanical properties such as hardness, softness and brittleness. (Business Dictionary, 2019). Heat treatment also is considered as a term which is used to describe the controlled heating and cooling of materials for the purpose of altering their structures and properties. Figure 3 shows the difference between heated and non-heated surfaces. The same material can be made weak and ductile for ease 
in manufacture, and then retreated to provide high strength and good fracture resistance for use and application. Because both physical and mechanical properties (such as strength, toughness, machinability, wear resistance and corrosion). (Black and Kosher 2013)

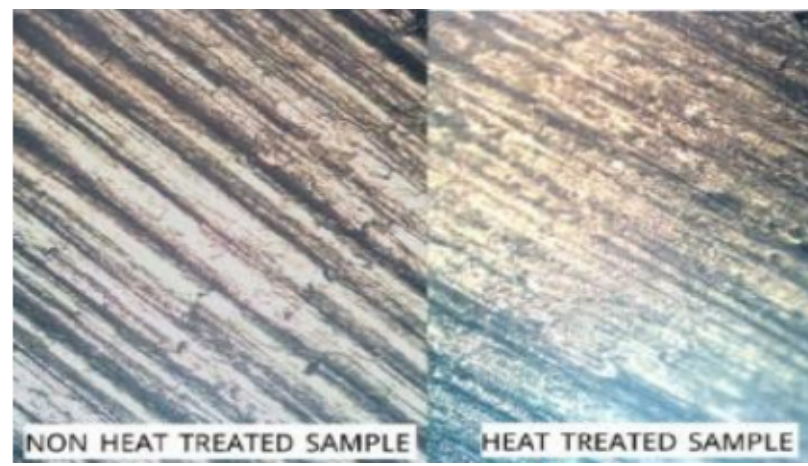

Figure 3 heated and non-heated surfaces (Patwari, Imam and Chowdhury, 2011)

Heat treatment is divided into several sections which are hardening, tempering, annealing, and normalizing, quenching and surface hardening. Hardening does involves the steel heating, Figure 4, by keeping it in an appropriate heat temperature until pearlite are transformed into austenite, then quenching it rapidly in Oil or water, the heat takes place depending upon the carbon content in the steel which is used. Heating time have to be increased ensuring that the core also will be transformed fully into austenite. Microstructure of the hardened steel part is ferrite, cementite or martensitic. (Sinit। 2019) shows

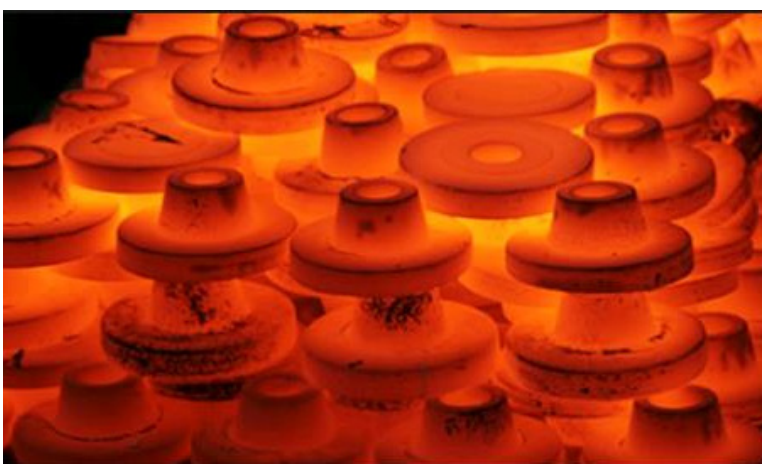

Figure 4 hardening process (Deck, 2019)

Hardening process of steel which has been hardened and quenched for a specific period of time so that metal can be equilibrated. Strength and hardness is obtained depending on the temperature at which tempering is carried out. As known higher temperature will result to higher ductility but at the same time low hardness and strength, as for the opposite thing were low tempering temperature will produce low ductility, but high hardness and strength. This operation is usually preformed on every carbon steel that has been hardened to reduce the brittleness so it can be used effectively in desired applications. (Sinit 2019)

Annealing always involves treating steel up to high degrees of temperature, then cooling it slowly to the room temperature as shown in Figure 5.

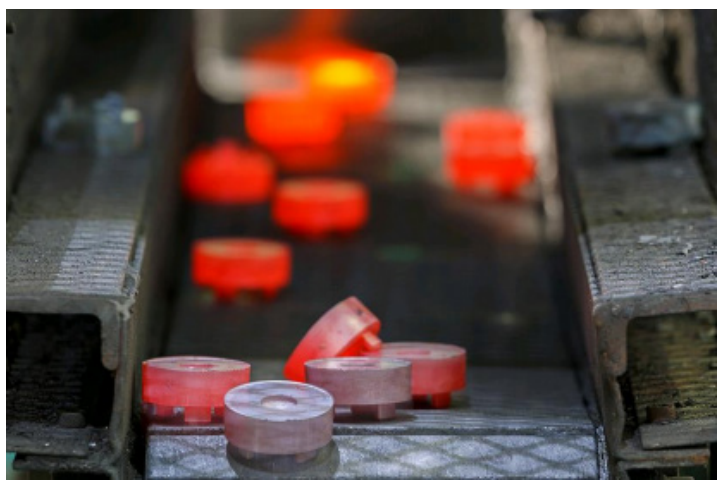

Figure 5 Tempering \& annealing process (Reliance Foundry, 2019)

The resulting structure possess high toughness and ductility and at the same time low hardness. It's usually performed by the heating of the components to the appropriate temperature, soaking it at that specific heat. Before the cold forming process steel is annealed to reduce the load requirements and energy. (Sinit 2019).

Figure 6 and 7 shows Normalizing process that keeping the steel at a specific temperature for a period of time, then cool it in air.

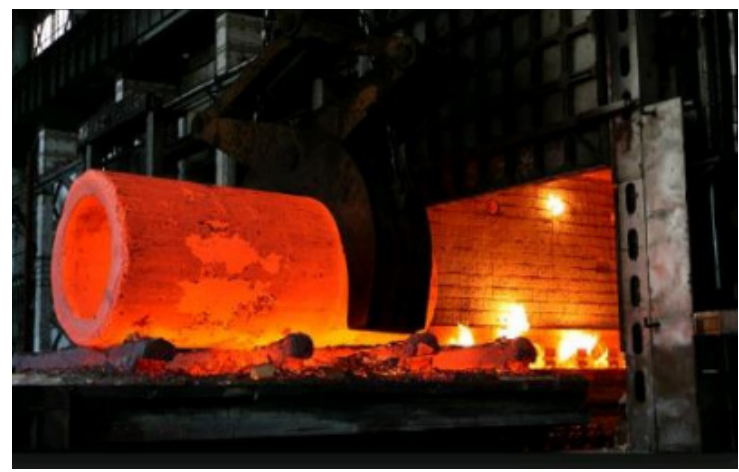

Figure 6: Normalizing process (Exporters India, 2019)

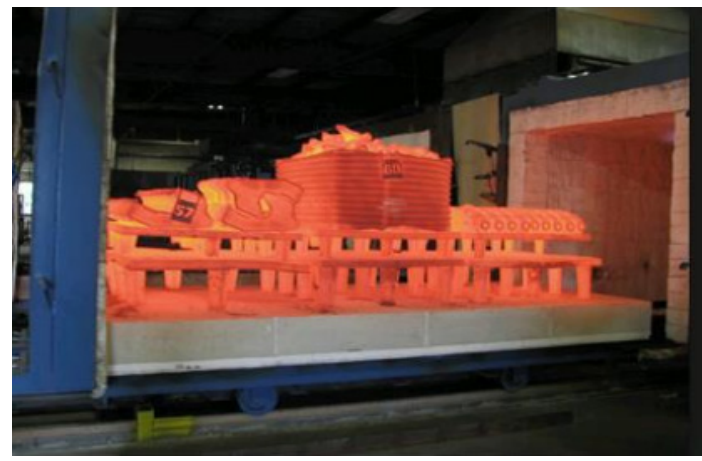

Figure 7 normalizing process (Exporters India, 2019)

The structure which will be resulted is a mixture of cementite and ferrite which has higher hardness and strength but also has low ductility. Normalizing is performed on structural components and structures that will be subjected to machining, because it does 
improve the carbon steels during the machining process. (Sinit 2019)

Quenching is another process of heat treatement, since quenching happens from the outside-in, huge objects can involvement the pressures of rapid crystallization leading to internal pressure in the metal. Sometimes those forces can create cracks if quenching was moreover extreme as shown in Figure 8 shows the quenching process. Hence, due to this reason, using water for the quenching process is not very common for huge steel items, as it causes a very quick drop in the objective temperature which can lead or causes a cracks to be formed.

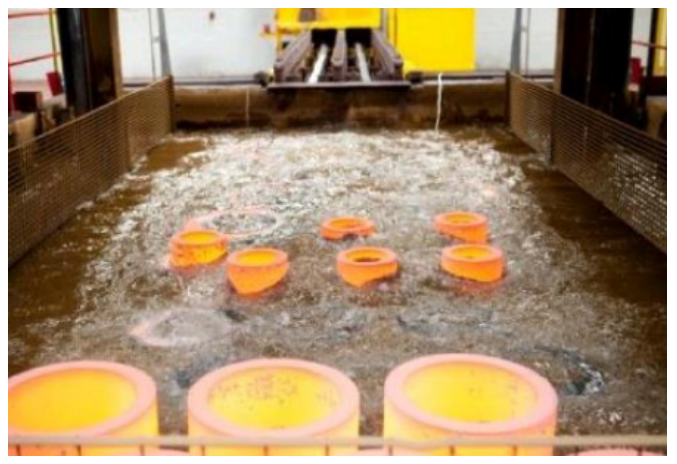
2019)

Figure 8 shows the quenching process (Conmecheng,

Air and oil both cool slightly less toughly. However, not only steels which are used to quenched for hardening. Water quenching is used in a foundry. Non-steel metals may not suffer the same internal pressures because their phases and molecular structures will be different. Manganese is waterquenched at much higher temperatures than steel, without cracking. However, the difference in temperature is so great that any quenching deals with a lot of energy that can go awry! Figure 9 shows how can quenching be dangerous to human as well as environments (Reliance Foundry, 2019).

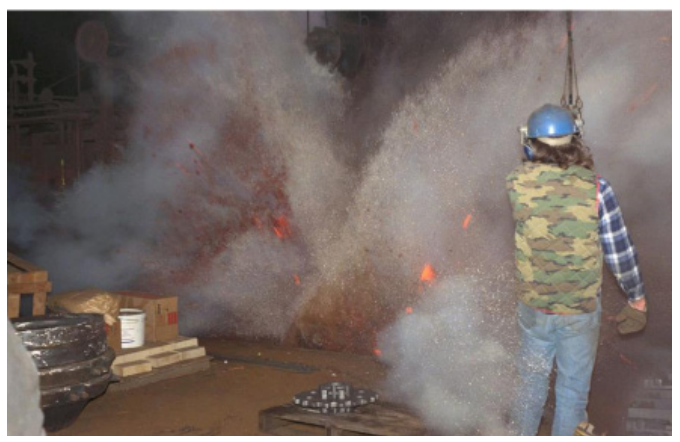

Figure 9: air quenching

\section{Surface hardening}

Surface hardening is needed in several engineering applications. It's important to have the texture or the surface of the component hard to resist erosion and wear. While keeping toughness and ductility same to hold up shock loading and impact. It can be achieved only by local quenching and austentitizing also diffusion of Harding elements such as carbon or nitrogen into the surface. The processes which are involved in such as this purpose are known as flame hardening, carbo-nitriding, induction hardening and nitriding. (Sinit 2019)

\section{Surface roughness}

Surface roughness is a measurable characteristics based on the roughness deviation. Surface roughness can be defined as the average of vertical deviations from the nominal surface over specified surface length. Surface roughness assessment is very important for many basic problems such as friction, contact deformation, heat, current electrical conductivity, tight contact joints, and placement accuracy. For this reason, surface roughness has been the subject of empirical and theoretical investigations for decades. Real surface geometry is so complex that a limited number of parameters cannot be fully described. If the number of parameters used increases, a more accurate description can be obtained. This is one of the reasons for introducing new parameters for surface assessment. Surface roughness parameters are classified into three groups according to their functions. These groups are defined as spacing parameters, spacing parameters, and mixed parameters. This paper describes definitions and mathematical formulas for about 59 roughness parameters. This set of surface roughness parameter was used in a new computer vision package called (Surf Vision) developed by the authors. In the package, these definitions were expanded to calculate the 3D terrain of the various samples. (Gadlmawla and Solaiman 2002) Roughness parameters Rt: height between the deepest valley and highest peak on the evaluation length, RP: highest peak from the mean line which is defined on sampling length, Rv: deepest point (valley) from the mean point, Ra: the average of material roughness and RZ: the maximum height of the profile (RP $+R V$ ). (Groover, 2017) 13 Roughness height: it's the height of the wrongdoing with the respect of the reference point. Its measured in $\mathrm{mm}$ to micro inches, also its known as the height of disparity. Roughness width: is the parallel distance to the nominal surface between peaks or ridges which create the pattern of the roughness. Roughness width cut off: The greatest spacing of respective surface irregularities to be included in the measurement of the average roughness height. It should always be greater than the roughness width in order to obtain the total roughness height rating. It is used to differentiate between roughness and waviness. The cut-off length should be at least 2.5 times the peak-topeak spacing of the profile roughness. This means that at least two peaks and valleys are found in each cut-off length. (Iugaza, 2019) As mentioned below Figures 10 and 11 shows the roughness parameters on the surface

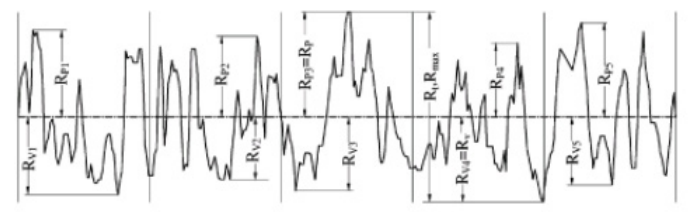

Figure 10: roughness parameters (Keyence, 2002) 


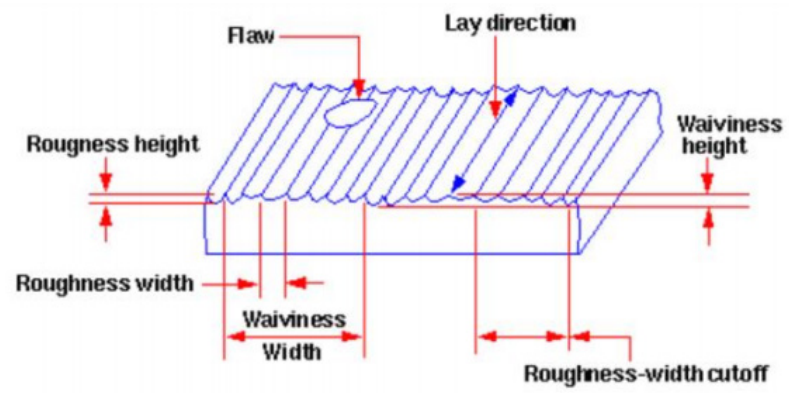

Figure 2.11: Surface characteristics (Iugaza, 2019)

\section{Turning operation}

Turning is a form of machining, a material removal process, which is used to create rotational parts by cutting away unwanted material. The turning process requires a lathe work piece, fixture and cutting tool. The work piece is a piece of pre-shaped material that is secured to the fixture, which itself is attached to the turning machine, and allowed to rotate at high speeds. The cutter is typically a single-point cutting tool that is also secured in the machine as shown in Figure 12, although some operations make use of multi-point tools. The cutting tool feeds into the rotating work piece and cuts away material in the form of small chips to create the desired shape. Turning is used to produce rotational, typically axi-symmetric, parts that have many features, such as holes, grooves, threads, tapers, various diameter steps, and even contoured surfaces. 15 Parts that are fabricated completely through turning often include components that are used in limited quantities, perhaps for prototypes, such as custom designed shafts and fasteners. Turning is also commonly used as a secondary process to add or refine features on parts that were manufactured using a different process. Due to the high tolerances and surface finishes that turning can offer, it is ideal for adding precision rotational features to a part whose basic shape has already been formed. (Turning Process, 2019)

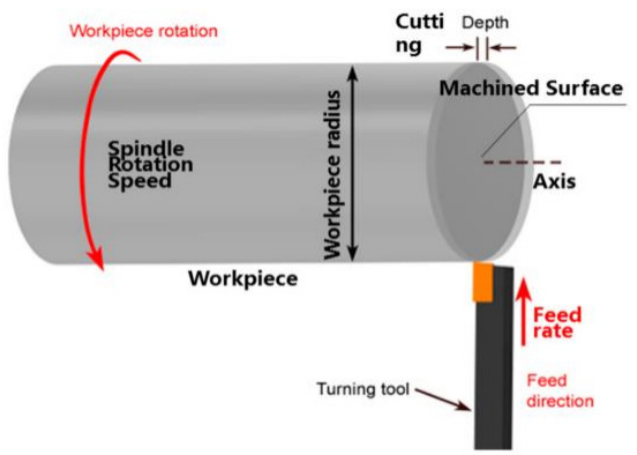

Figure 12 Turning operation (Turning Process, 2019)

Cutting tool Machines are certainly evolving. They are faster and more accurate. But cutting itself is not only gradual evolution, it is fundamentally changing. Today's machined parts in turning machines may not has the perfect finishing just because of the cutting tool which affect the shape of the surface. Many types of tools from high carbon steel to ceramics and diamonds are now used as cutting tools in the metallurgical industry. It is important to take into account the differences between the tools' materials, the differences in the differences, and the correct application of each material. (Altin
Fourth Middle East College Student Research Conference, Muscat, Sultanate of Oman

et al. 2007)

\section{Cutting parameters}

The selection of optimal cutting parameters is very important issues for every machining process in order to enhance the quality of machining products and reduce the machining costs, the main factors of cutting parameters are: material machinability, cutting tool material, depth of cut, spindle and cutting speed, feed rate, coolant and machine/spindle power. (Cutting Parameters Basics, 2019) Ganta and Kumar, focused on the effect of input process parameters on surface roughness on mild steel with different heat treatment processes. The experiment was conducting using lathe $\mathrm{CNC}$ machine. Different feed rate and rotational speed as the input parameters. Different heat process were used in the experiment as: annealing, quenching and normalizing. Talysurf was used to measure the surface roughness, Talysurf is a high accuracy instrument range capable of simultaneous surface finish and contour measurement. Surface roughness is minimum at $\mathrm{N}=17$ $1500 \mathrm{rpm}, \mathrm{F}=0.1 \mathrm{~mm} / \mathrm{rev}$ at normalizing followed by quenching, annealing, and standard. Comparing all the processes at rotational speed for $\mathrm{N}=500 \mathrm{rpm}$ and $1000 \mathrm{rpm}$, the minimum surface roughness is obtained for quenching heat treatment process.

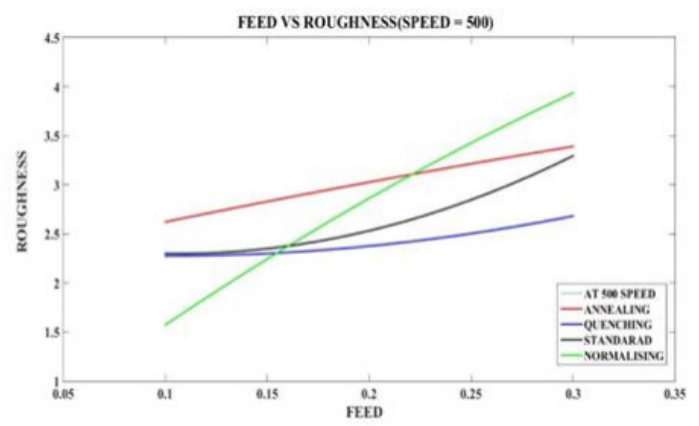

Figure 13: The relation between the roughness and all processes.

As shown in the above figure we can notice that Graph between feed and surface roughness for all three cases annealing, normalizing and quenching respectively at all three levels of rotational speed It is observed that surface finish is better in normalizing process followed by annealing, quenching and standard. (Ganta and Kumar, 2017) Nandani and Kulkarni, work has been carried out to find the optimum conditions for surface roughness using suitable methods like Taguchi and ANOVA (Analysis of Variance) for Mild Steel (EN-8 grade) material. The machining parameters like Cutting speed, feed and depth of cut are optimized by measuring the Surface Roughness of the material. The surface roughness of materials is checked using a device called Surtronic S128 which is Taylor Hobson AMETEK make. The experiment conducted on MIDAS turning machine (lathe machine) for mild steel bars, which is $50 \mathrm{~mm}$ length and $44 \mathrm{~mm}$ diameter by keeping chuck pressure $25 \mathrm{~kg} / \mathrm{cm}^{2}$, coolant pressure 5 bar and cutting length $25 \mathrm{~mm}$ during machining. Surface roughness measured for effective length $2.5 \mathrm{~mm}$ using a device called Surtronic S128. In Taguchi for three level of factors and three cutting parameters, L9 orthogonal arrays used. The objective function in Taguchi is $\mathrm{S} / \mathrm{N}$ ratio where ' $\mathrm{S}$ ' represents signal and ' $\mathrm{N}$ ' represents noise. There are three characteristics of $\mathrm{S} / \mathrm{N}$ ratio i.e. smaller the better, nominal the better and higher the better. The results showed that for Mild steel material feed is the significant parameter influencing the surface roughness. Taguchi design is used to find the optimum cutting parameters for $\mathrm{CNC}$ turning 
center. Experimental results were analyzed by using ANOVA. In Taguchi the first step is to find the $\mathrm{S} / \mathrm{N}$ ratios for each experimental values. The second step is to find the optimum cutting parameters from calculated level values. Then ANOVA is used to find the significant factor which affects the surface roughness. (Nandani and Kulkarni, 2018). Bin Ramli, presented in his journal an investigation about surface roughness of mild steel operation while using a carbide cutting tool. (Mohammed, 2018) investigated in this study the effect of heat treatment which are annealing, normalizing, hardening and tempering on the mechanical properties which are the hardness, toughness, percentage reduction and ultimate tensile strength. The following conclusion was made from the investigation of the effect of heat treatment on the mechanical properties: The tensile strength, yield strength and carbon steel stiffness increased with plastic deformation while the softness and strength of shock decreased due to the impact of hardening of stress. Normalization also increased tensile strength and hardness of plasticized samples. This treatment is recommended as a final treatment after manufacturing. The hardened sample showed higher resistance to tensile strength and stiffness with lower elasticity and impact strength than other heat treated samples. Hardness is strongly recommended when strength and rigidity are the main characteristics desired in the design. Mechanical properties of NST 37-2 steel can be changed through different thermal treatments. The results obtained confirm that the improvement in the mechanical properties that can be obtained by subjecting NST 37-2 the steel to different heat coefficients investigated in this study. (Patwari, Mahmood and Arif, 2012), presented in their paper the details of improvement of machinability of mild steel using magnetic cutting during turning operation. Improvement of machinability was evaluated in terms of tool life, surface roughness and chip morphology. Machine tool chatter is a type of intensive self-excited vibrations of individual components of Machine-Tool-Fixture-Work (MTFW) system. Chatter causes unwanted excessive vibratory motion in between the tool and the work-piece causing adverse effects on the product quality and machine-tool and tool life. In addition to the damage of the work-piece surface due to chatter marks, the occurrence of severe chatter results in many adverse effects, which include poor 20 dimensional accuracy of the workpiece, reduction of tool life, and damage to the machine. Chatter is formed as resonance phenomena during machining because of the instability of the closed-loop system formed by machine tool structure and metal-cutting process. In this study, magnets were used to avoid the chatter formation zone and its effect on machinability was investigated. Improvements in tool life and surface finish were observed during magnetic cutting of the mild steel. An obvious change in the chip behavior was also present. These observations further enhance the possibility of using this magnetic cutting to eliminate the chatter formation zones and hence eliminate the adverse effect of chatter on machinability. (E., Kamal and Ogunjirin, in 2019) conducted a study in order to enhance the mechanical properties of mild steel materials using studs and bolts. Heat process at $900^{\circ} \mathrm{C}$. Results of the test showed positive changes in the properties of the mild steel material, in term of toughness, ductility, high tensile strength and hardness. Quenching using water had the highest toughness, highest tensile strength and bending at yield. Also it recorded the lowest ductility of $28.5 \%$ comparing with other coolant types. Water proved to be the best quenching (cooling) type to achieve those desirable qualities among all quenching types.
(Patwari, Imam and Chowdhury, 2011) investigate the effect of heat treatment on machinability improvement of mild steel during turning operation. In the experimental investigations heat treated mild steel under full annealing conditions and normal mild steel has been considered as two work materials. Tool life, surface roughness and chip morphology were investigated during the experiments for both the work materials. Turning operation tests were conducted for mild steel machining using lathe machine with automatic feed. Machining was performed at room temperature in dry cutting conditions for both annealed and non-annealed mild steel. Softening of materials during heat treatment helps in substantially increasing tool life as tool wear is delayed. It has been observed that surface quality has been improved and different chip type has also been observed during the machining of annealed compare to machining of non-annealed mild steel. From the experimental findings, the obtained improvement reflects the feasibility of using this technique as a cost effective machining process

\section{Methodology}

Nowadays low carbon steel or as it is known mild steel plays a significant role in the industries operation. Therefore grinding and finishing the product is one of the processes that the company follows in order to get the product to its final shape. Enhancing the surface roughness of low carbon steel could prevent the effort of finishing the final product. Several information were collected from literature review, journal articles, websites and books. In order to obtain satisfied data for this project. Previous experiments also were revisited to be fully aware of the project incomes and outcomes. Several specimen has been used during the experiments (up to 10 specimens), all specimen which was used for the experiments are made of mild steel, and all specimen had the same measurement and same material. The furnace which is in the (MEC) Mechanical Lab was used to increase the temperature of the bars to a certain temperature which are $650^{\circ} \mathrm{C}$ and $900^{\circ} \mathrm{C}$ (Heating process). After applying those to the heat quenching, annealing and normalizing was used as the coolant method, which were by using quenching by: (water, Oil and water solution), annealing by switching of the oven at the same time the specimen was remained in the furnace until it return to its normal heat. The third and last coolant method was normalizing by leaving the specimen in a room with a normal temperature to cool down after applying it to the specific heat degree which is mentioned above. After the temperature of all specimen returns to its normal degree, OD turning will be made to all specimen using lathe machine, but before the machining part grindings will be used to clear the specimen surface from all the impurities.at the final step surface roughness measurement tester will be used to measure the surface roughness of all specimen.

\section{Types and preparation of specimen}

A raw long mild steel bar was cut into several pieces with the length of $250(\mathrm{~mm})$ and thickness of $19.6(\mathrm{~mm})$. In order to get an accrue result, all specimen which will be used to conduct the experiment on has the same measurements. The total of all specimen was 20 specimen, but only 10 specimen was used and they were divided into 2 sets each sets carries 5 specimen. The first set of specimens was heat treated up to $6500 \mathrm{C}$, while the other set was heat treated up to $9000 \mathrm{C}$. The remaining 10 specimen was kept as a backup specimens in order to use them if there was any mistakes or errors during the turning operation.

\section{Coolant medium}

Three types of coolant were used in the experiments which 
are quenching, annealing and normalizing. Water, salted water and oil was used for the quenching method on the other hand for annealing the specimen was kept inside the furnace to cool down slowly and at the same time the furnace was switched of but for the normalizing the specimen was kept in the lab with normal room temperature in order to cool down slowly. Based on the researches that has been done on this project it was noticed that, whenever water is used as a quenching medium it will extract heat much faster than oil, while the oil will extract heat much slower than the water are the salted water, therefore the spacemen cooling will be much slower than salted water and normal water. Water cooling will usually give you higher hardness but a more stressed component. Cooling the oil will produce less stress and moderate hardness. (Tikle, 2017)

\section{Experimental set-up}

The project is based on experiments and in order to achieve them in a precise form machines and devices were used to complete the experiments, Also in order to achieve the objectives of this report. The specimens measurements were carefully taken with the digital Vernier caliper for precise results, furnace was used then to heat treat the specimen, lathe machine also took action 24 on specimens for turning operation and finally measurement tester was used for measuring the surface roughness of the heat treated specimens to compare between the gotten results.

\section{Turning machine}

Turning operation is a major part in the project, and in order to achieve the main aim in this project lathe machine was used in the turning operation. The machine type is echo ENG (TP250DS/1500) lathe machine. Some of the machine characteristics are: Voltage: $400 \mathrm{~V}$, Phases: 3, frequency: 50 Hz, Capacity: 4/55 kVA, cutting max: $1 \mathrm{kA}$ and Protection Degree: IP54 as shown in Figure 13.

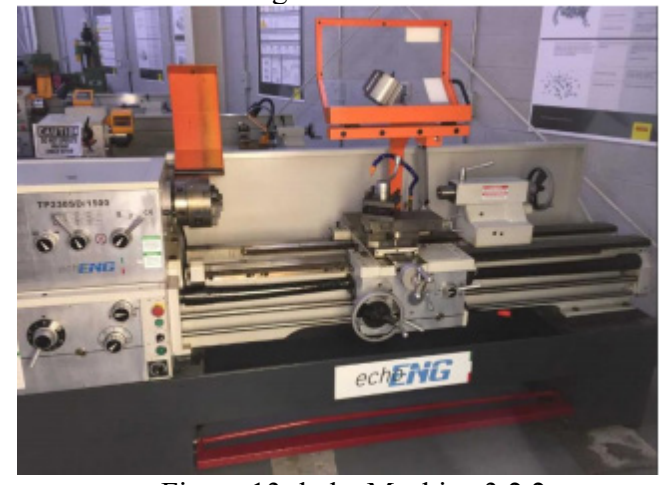

Figure 13: lathe Machine 3.2.2

\section{Cutting tool}

The cutting tool is any tool used to remove material from the workpiece by shear distortion. The pieces can be achieved by single-point or multi-point tools. Single-point tools are used for turning and shaping operation. In this experiment, cutting tool was used in each set of turning $\left(650^{\circ} \mathrm{C}\right.$ specimen's sets and $900^{\circ} \mathrm{C}$ specimens set), which means 2 cutting tools was used as shown in Figure 14 carbide cutting tool. (Definitions.net, 2019). For each type of heat treated specimens the cutting speed, feed rate and depth of cut are 830 $\mathrm{rpm}, 0.226 \mathrm{~mm}$ and $1.5 \mathrm{~mm}$ respectively. Another experiment was conducted with the same cutting parameter while feed rate was changed from $0.226 \mathrm{~mm}$ into $0.113 \mathrm{~mm}$.

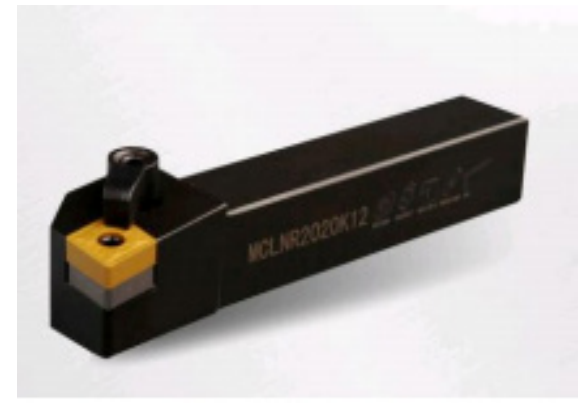

Figure 14: carbide cutting tool (SANT, 2019)

\section{Furnace}

The furnace is an important factor in this experiments, because it was used for the heat process. Furnace type which was used to conduct this experiments is furnace as shown in Figure 15. It could reach up to $1300^{\circ} \mathrm{C}$ of temperature. The 10 specimen from each set was divided into two sets, each set carries five specimens which was fitted into the furnace. The temperatures which were used are $650^{\circ} \mathrm{C}$ and $900^{\circ} \mathrm{C}$, the main reason of using those specified temperatures was just like it was planned to push the mild steel temperature above the eutectoid point which is $723^{\circ} \mathrm{C}$. The eutectoid point is the point where the mild steel shape starts to changes if the mild steel temperature exceeded it therefore the temperature $900^{\circ} \mathrm{C}$ was used to study how could the change of the material structure effect the surface roughness.

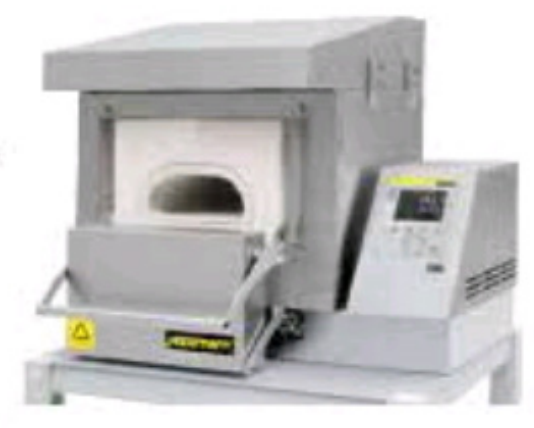

Figure 15: furnace used in the experiments

\section{Data collection and measurements Measurement tool}

The measurements of the specimens can play a major role in the experiments results, if the specimen sizes wasn't equal this could affect the results. Digital Vernier caliper was used to measure the specimen thickness and length to make sure that all specimen has the same sizes as shown in Figure 16.

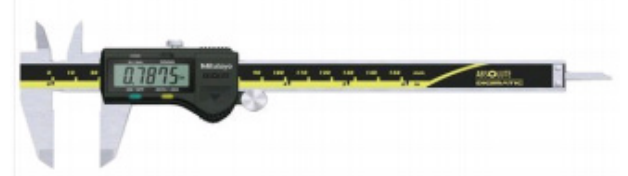

Figure 16: Digital Vernier caliper (Mart, 2019) 


\section{Journal of Student Research}

Figure 17 shows the measurement tester which was used to measure the surface roughness value of all specimens in the experiment

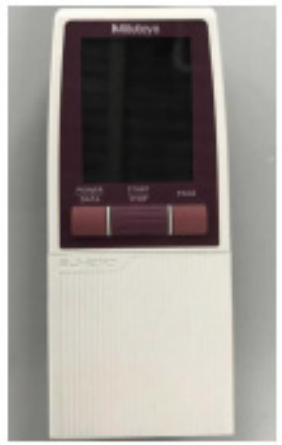

Figure 17 measurement tester

\section{Result Analysis and Discussion}

The roughness values was taken for all 10 specimen from two different sets, first set contained 5 specimens and were heated up to $650^{\circ} \mathrm{C}$, second set also contained 5 specimen and were heated up to $900^{\circ} \mathrm{C}$. As mentioned previous the coolants methods used in both sets are water, Oil, Salted water, Annealing and normalizing. 2 specimen was taken from each coolant type, one specimen from the $650^{\circ} \mathrm{C}$ set and from the $900^{\circ} \mathrm{C}$ set, then turning operation toke place at feed rate of $0.226 \mathrm{~mm}$, speed of $830 \mathrm{rpm}$ and depth of cut was $1.5 \mathrm{~mm}$. All specimen was turned with the same fixed cutting parameters. After executing the turning operation, roughness tester took place and it was used to measure the roughness of each specimen from three different places also the average of all specimens was taken.

From Table 1 it can be noticed that most of the $900^{\circ} \mathrm{C}$ heated specimen has less roughness values.

Table 1, Data at feed of $0.226 \mathrm{~mm}$
Fourth Middle East College Student Research Conference, Muscat, Sultanate of Oman

\begin{tabular}{|c|c|c|c|c|}
\hline Coolmant type & $650^{\circ} \mathrm{C}$ & $900^{\circ} \mathrm{C}$ & $\begin{array}{c}\text { Specimsens figures } \\
\text { at } 650^{\circ} \mathrm{C}\end{array}$ & $\begin{array}{c}\text { Specimens figures } \\
\text { at } 900^{\circ} \mathrm{C}\end{array}$ \\
\hline Winer quenching & $\begin{array}{c}\mathrm{R}_{\mathrm{s1}}=6.25 \mu_{\mathrm{x}} \\
\mathrm{R}_{\mathrm{2}}=6.20 \mu_{\mathrm{x}} \\
\mathrm{R}_{\mathrm{a}}=6.1 \mu_{\mathrm{x}} \\
\text { Average }= \\
6.18 \mu_{\mathrm{s}}\end{array}$ & $\begin{array}{c}R_{\mathrm{si}}=5.46 \mu_{\mathrm{s}} \\
\mathrm{R}_{\mathrm{s2}}=4.88 \mu_{\mathrm{s}} \\
\mathrm{R}_{\mathrm{s}}=5.24 \mu_{\mathrm{s}} \\
\text { Average }=5.19 \\
\mu_{\mathrm{s}}\end{array}$ & & \\
\hline $\begin{array}{l}\text { Salted waser } \\
\text { quenching }\end{array}$ & $\begin{array}{c}\mathrm{R}_{\mathrm{al}}=3.24 \mu_{\mathrm{s}} \\
\mathrm{R}_{\mathrm{w}}=4.94 \mu_{\mathrm{s}} \\
\mathrm{R}_{\mathrm{w}}=1.9 \mu_{\mathrm{s}} \\
\text { Average = } \\
3.36 \mu_{\mathrm{s}}\end{array}$ & $\begin{array}{c}R_{41}=5.6 \mu_{\mathrm{s}} \\
R_{\mathrm{s} 2}=5.5 \mu_{\mathrm{s}} \\
\mathrm{R}_{\mathrm{a}}=4.8 \mu_{\mathrm{s}} \\
\text { Average }=5.3 \\
\mu_{\mathrm{s}}\end{array}$ & & \\
\hline Oil quenching & $\begin{array}{c}\mathrm{R}_{21}=7.00 \mu_{x} \\
\mathrm{R}_{22}=7.79 \mu_{x} \\
\mathrm{R}_{21}=9.5 \mu_{s} \\
\text { Average }= \\
8.09 \mu_{x}\end{array}$ & $\begin{array}{c}\mathrm{R}_{\mathrm{al}}=7.60 \mu_{\mathrm{s}} \\
\mathrm{R}_{\mathrm{L2}}=8.18 \mu_{\mathrm{s}} \\
\mathrm{R}_{\mathrm{\alpha}}=6.58 \mu_{\mathrm{s}} \\
\text { Average }=7.45 \\
\mu_{\mathrm{s}}\end{array}$ & & \\
\hline Annealing & $\begin{array}{c}\mathrm{R}_{21}=7.05 \mathrm{H}_{\alpha} \\
\mathrm{R}_{22}=9.97 \mathrm{H}_{\mathrm{s}} \\
\mathrm{R}_{23}=9.21 \mathrm{H}_{\mathrm{s}} \\
\text { Average = } \\
8.74 \mathrm{H}_{\mathrm{s}}\end{array}$ & $\begin{array}{c}\mathrm{R}_{21}=5.54 \mu_{\mathrm{s}} \\
\mathrm{R}_{22}=6.23 \mu_{\mathrm{s}} \\
\mathrm{R}_{2}=7.00 \mu_{\mathrm{s}} \\
\text { Average }=6.25 \\
\mu_{\mathrm{s}}\end{array}$ & & \\
\hline Normalizing & 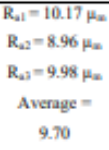 & $\begin{array}{c}R_{21}=8.28 \mu_{\mathrm{s}} \\
R_{22}=9.39 \mu_{\mathrm{s}} \\
R_{2}=9.54 \mu_{\mathrm{s}} \\
\text { Avernge }=9.07 \\
\mu_{\infty}\end{array}$ & & \\
\hline
\end{tabular}

Figure 18, Results has shown that salted water specimen quenched at $650^{\circ} \mathrm{C}$ has the less surface roughness with an average of $3.36 \mu \mathrm{m}$ Comparing to other specimen the closest average was the water quenched specimen at $900^{\circ} \mathrm{C}$ with a roughness average of $5.19 \mu \mathrm{m}$. On the other hand the highest roughness average value was measured at the normalized specimen to be more accurate at the degree $650^{\circ} \mathrm{C}$ it was $9.70 \mu \mathrm{m}$ while at $900^{\circ} \mathrm{C}$ was $9.07 \mu \mathrm{m}$, which shows that $650^{\circ} \mathrm{C}$ specimens has highest roughness values than $900^{\circ} \mathrm{C}$ specimens except for the salted water quenched specimen.

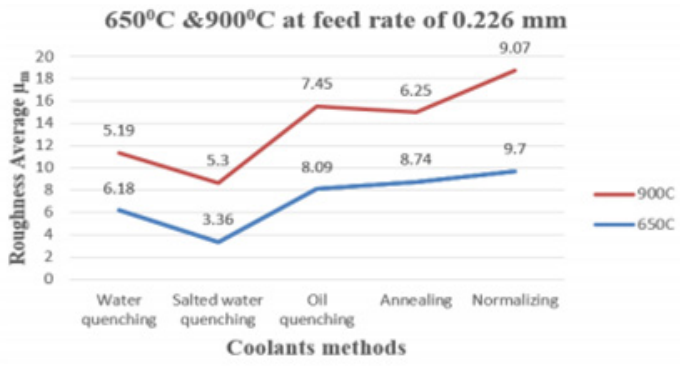

Figure 18: heated specimens at $650^{\circ} \mathrm{C} \& 900^{\circ} \mathrm{C}$, speed: $830 \mathrm{rpm}$ and feed: $0.226 \mathrm{~mm}$

Result after changing the feed rate into $0.113 \mathrm{~mm}$

Table 2 shows the roughness values of the second turning operation that has been conducted using the same fixed turning cutting parameters which are, speed at $830 \mathrm{rpm}$ and depth of cut $=1.5 \mathrm{~mm}$, while the feed rate was changed into $0.113 \mathrm{~mm}$.

Table 2: Data at feed of $0.113 \mathrm{~mm}$ 


\section{Journal of Student Research}

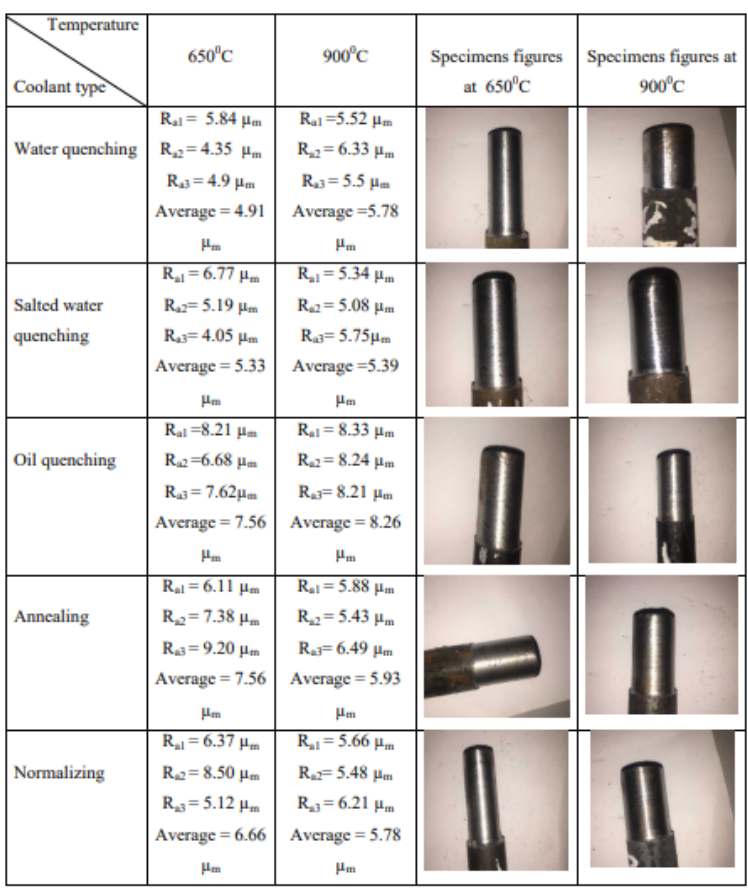

Same process was followed regarding the specimens heat temperature and coolant types. From table 2 it can observe that the results of this experiment are quite different from the results of the first experiment, although only the feed rate has changed into $0.113 \mathrm{~mm}$. Water quenching at $650^{\circ} \mathrm{C}$ was found that it has the less roughness average value by $4.91 \mu \mathrm{m}$, then follows it salted water quenching with $5.33 \mu \mathrm{m}$, normalizing $6.66 \mu \mathrm{m}$, finally oil quenching and annealing with same value of roughness average $=7.56 \mu \mathrm{m}$. On the other hand at $900^{\circ} \mathrm{C}$ salted water quenching has got the less value by $5.39 \mu \mathrm{m}$ roughness average then follows it water quenching and normalizing with $5.78 \mu \mathrm{m}$ roughness average, annealing by $5.93 \mu \mathrm{m}$ and finally comes the oil quenching with a value of $8.26 \mu \mathrm{m}$. it was observed that oil quenching at $900^{\circ} \mathrm{C}$ got the highest roughness average among all other specimens in different heat degrees when feed is $=0.113 \mathrm{~mm}$.

Figure 19 shows the differences of roughness average for each coolant type, at $650^{\circ} \mathrm{C} \& 900^{\circ} \mathrm{C}$ when speed is 830 $\mathrm{rpm}$ and feed rate is $0.113 \mathrm{~mm}$.

$650^{\circ} \mathrm{C} \& 900^{\circ} \mathrm{C}$ at feed rate of $0.113 \mathrm{~mm}$

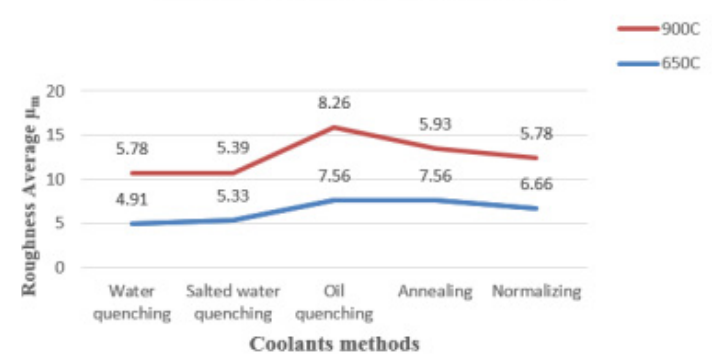

Figure 19: heated specimens at $650^{\circ} \mathrm{C} \& 900^{\circ} \mathrm{C}$, speed: $830 \mathrm{rpm}$ and feed $=0.113 \mathrm{~mm}$

After all experiments was applied, it was discovered that salted water quenched specimen at $650^{\circ} \mathrm{C}$ with $0.226 \mathrm{~mm}$ feed of rate has recorded the lowest roughness average among all
Fourth Middle East College Student Research Conference, Muscat, Sultanate of Oman

specimens, while results has also shown that the highest roughness average value was measured at the normalized specimen to be more accurate at the degree $650^{\circ} \mathrm{C}$ and feed rate of $0.226 \mathrm{~mm}$ recorded $9.70 \mu \mathrm{m}$ roughness average.

\section{Conclusions and Recommendations}

It was concluded that heating up to $900^{\circ} \mathrm{C}$ will create a better surface roughness than $650^{\circ} \mathrm{C}$ this because of changing its structure and been more stable. Also heated up to $900^{\circ} \mathrm{C}$ for all specimens machined with a feed rate of $0.226 \mathrm{~mm}$ has shown less surface roughness values while specimens which was heated up to $600^{\circ} \mathrm{C}$ showed higher values expect for salted water. Hence, even though $900^{\circ} \mathrm{C}$ has changed the specimen structure and mechanical properties of the specimen material (low carbon steel) it has still shown less roughness. Therefore it was concluded that oil quenching at $900^{\circ} \mathrm{C}$ got the highest value of surface roughness with $8.26 \mu \mathrm{m}$ among all the specimens when machined with feed of $0.113 \mathrm{~mm}$. While water quenched specimen at $650^{\circ} \mathrm{C}$ has got $4.91 \mu \mathrm{m}$, the less roughness average.

\section{References}

Altin, A., Nalbant, M. and Taskesen, A. (2007) "The Effects Of Cutting Speed On Tool Wear And Tool Life When Machining Inconel 718 With Ceramic Tools". Materials \& Design 28 (9), 2518 2522

Bin Ramli, M. (2018). INVESTIGATION ON SURFACE ROUGHNESS OF MILD STEEL USING COATED CARBIDE CUTTING TOOLS. [Online] Umpir.ump.edu.my. Available at: http://umpir.ump.edu.my/id/eprint/900/1/Mohamad_Rais_Ramli.pdf [Accessed 29 Dec. 2018]

Black, J. and Kosher, R. (2013) DEGARMO's. 11th edn. New Delhi: wiley india

Bollards by Reliance Foundry. (2019). Heat Treatment: Life of a Casting Series. [Online] Available at: https://www.reliancefoundry.com/castings/tempering-steel\#gref [Accessed 17 Jan. 2019].

BusinessDictionary.com. (2019). What is heat treatment? Definition and meaning. [Online] Available at: http://www.businessdictionary.com/definition/heat-treatment.html

Conmecheng.com. (2019). Water Quench \& Temper. [online] Available at: http://www.conmecheng.com/heattreatment/servicesdetail.php?id=183 [Accessed 17 Jan. 2019].

Deck India engineering Pvt. Ltd. (2019). Hardening. [Image] Available at: http://www.deckindia.com/ [Accessed 17 Jan. 2019].

Definitions.net. (2019). What does cutting tool mean?. [online] Available at: https://www.definitions.net/definition/cutting+tool

Exportersindia.com. (2019). normalizing furnace Manufacturer \& Manufacturer from, India | ID - 3492556. [Online] Available at: https://www.exportersindia.com/therelek-engineerspltd/normalizing-furnace-3492556.htm [Accessed 17 Jan. 2019]. 
Gadlmawla, E. and Solaiman, H. (2002) "Material Processing Technology". Science Direct [online] 123 (1), 133-145. available from 32

https://www.sciencedirect.com/science/article/pii/S0924013602 000602\#! [15 January 2019]

Ganta, H. and Kumar, S. (2018). Effect of Process Parameters on Surface Roughness of Mild Steel with Different Heat Treatments in CNC Lathe. [online] Ijetsr.com. Available at: http://ijetsr.com/images/short_pdf/1510497868_65-71ietep867_ijetsr.pdf. Groover, M. (2017).

Groover's principles of modern manufacturing. 5th ed. Hoboken, New Jersey: John Wiley \& Sons, Inc., pp.144-146.

Harvey, R. (2018) What Is the Purpose Of Heat Treatment? Quora [online] available from https://www.quora.com/What-isthe-purpose-of-heat-treatment. [10 December 2018]

Mart, I. (2019). 0 150mm Digital Vernier Caliper Mitutoyo. [online] indiamart.com. Available at: https://www.indiamart.com/proddetail/0-150mm-digital-verniercaliper-mitutoyo12391372755.html

Metal Lathe Turning Steel (2019) available from [20 January 2019] Metal Cutting Parameters Basics (2019) available from [20 January 2019]

Mishra, A. (2019) Definition Of "Eutectic Point" [online] available from https://www.quora.com/What-is-the-definitionof-eutectic-point [11 January 2019]

Mohamed, D. (2018) "Enhancement of Mechanical Properties Of Mild Steel And Stainless Steel Through Various Heat Treatment Processes". International Journal For Research In Applied Science And Engineering Technology 6 (4), 384-388

Nandani, S. and Kulkarni, R. (2018). Optimization of surface roughness of mild steel (EN-8) using Taguchi and ANOVA. International Research Journal of Engineering and Technology (IRJET), [online] 04(05), pp.3411-3414. Available at: https://irjet.net/archives/V4/i5/IRJET-V4I5829.pdf. [Accessed 16 Dec. 2018].

Patwari, A., Imam, I. and chowdhry, A. (2011). Investigation of machinability improvement during turning operation of heat treated mild steel. Research Gate, [online] p.9. Available at: https://www.researchgate.net/publication/276930763_Investigati on_of_machinability_i

mprovement_during_turning_operation_of_heat_treated_mild_s teel [Accessed 17 Jan. 2019].

Patwari, A., Mahmood, M. and Arif, M. (2012). Improvement of Machinability of Mild Steel during Turning Operation by Magnetic Cutting. International Journal on Advanced Science, Engineering and Information Technology, 2(3), p.207.
PEMCO, K. (2019). nabertherm 30-3000 furnace - Google Search. [online] Google.com. Available at: https://www.google.com/search?q=nabertherm+303000+furnace \&tbm=isch\&tbs=rimg:CYbIZ4wX9CjNIjjiJGOC66O uIgXDBfNpFc6xcxe

eqAhOSPXu0g0ztCMRt6pGm0cc2_1xfnPSFSsYp3M0zErLFEJ7G yoSCeIkY4Lro64iEQnNVQ43dv11KhIJBcMF82kVzrERHpSkL WKXxn8qEglzF56oCE5I9REelKQtYpfGfyoSCe7SDTO0IxG3Ef_1 3eMFB1AWDKhIJ

qkabRxzb_1F8RJnCg3bziKBsqEgmc9L4VKxincxHIAI6r_1QpYK yoSCTTMSssUQnsb

ER6UpC1il8Z_1\&tbo=u\&sa=X\&ved=2ahUKEwi2_uLAyJrhAhVM yKQKHYUzAYIQ

9C96BAgBEBg\&biw=1042\&bih=875\&dpr=1\#imgrc=hshnjBf0KM $3 \mathrm{ffM} \mathrm{S}$.

Kumar, T. and Ajiboye, T. (2012) "Effect Of Heat Treatment Processes On The Mechanical Properties Of Medium Carbon Steel". Journal Of Minerals And Materials Characterization And Engineering 11 (02), 143-152

Sagbas, A. and Kahraman, F. (2018). [online]

Pdfs.semanticscholar.org. Available at: https://pdfs.semanticscholar.org/9202/e3e0d3fec3006a2a66f3152f62 ae1166698f.pdf. [Accessed 10 Dec. 2018].

Sinit, J. (2019) What Is Heat Treatment? Hardening, Tempering, Annealing, Normalizing, Surface Hardening [online] available from https://www.brighthubengineering.com/manufacturingtechnology/30476-what-is-heattreatment/ [15 January 2019] 34 Steemit.com. (2019). [online] Available at: https://steemit.com/chemicalsmaterials/@dennisharley/metal-heattreatment-market2018-size-share-demand-and-analysis-2023

[Accessed 17 Jan. 2019].

Tikle, N. (2017). What is the difference between water quenching and oil quenching?. [online] Quora. Available at: https://www.quora.com/What-is-the-difference-between-waterquenchingand-oil-quenching Turning Process, Defects, Equipment (2019) available from https://www.custompartnet.com/wu/turning [20 January 2019]

What Is Mild Steel? | Metal Supermarkets - Steel, Aluminum, Stainless, Hot-Rolled, Cold-Rolled, Alloy, Carbon, Galvanized, Brass, Bronze, Copper (2018) available from https://www.metalsupermarkets.com/what-is-mild-steel/. [8 December 2018] Yahoo Is Now Part Of Oath (2019) available from https://uk.answers.yahoo.com/question/index?qid=20081124110612 AAxL21O [14 January 2019] 